\title{
Antibacterial Effect of Garlic Aqueous Extract on Staphylococcus aureus in Hamburger
}

\author{
Amir Sasan Mozaffari Nejad ${ }^{1}$; Shahrokh Shabani ${ }^{2}$; Mansour Bayat ${ }^{3}$; Seyed Ebrahim \\ Hosseini ${ }^{2,}$ \\ ${ }_{2}^{1}$ Research Center for Molecular Medicine, Hamadan University of Medical Sciences, Hamadan, IR Iran \\ 2 Department of Food Science and Technology, Islamic Azad University, Science and Research Branch, Tehran, IR Iran \\ 3 Department of Pathobiology, Faculty of Veterinary Specialized Sciences, Islamic Azad University, Science and Research Branch, Tehran, IR Iran \\ ${ }^{*}$ Corresponding author: Seyed Ebrahim Hosseini, Department of Food Science and Technology, Islamic Azad University, Science and Research Branch, Tehran, IR Iran. Tel/Fax: +98- \\ 2144865474, E-mail: ebhoseini@srbiau.ac.ir
}

Received: June 23, 2013; Revised: January 18, 2014; Accepted: February 02, 2014

\begin{abstract}
Background: Using garlic is widespread in Iran and other countries as a medicine and a natural spice. Garlic is a potential inhibitor for food pathogens. Foods contaminated with pathogens pose a potential danger to the consumer's health. The use of garlic can increase the shelf life and decrease the possibilities of food poisoning and spoilage in processed foods.

Objectives: The aim of this study was to investigate the antibacterial effect of garlic aqueous extract on growth of Staphylococcus aureus bacteria.

Materials and Methods: In this study, the garlic aqueous extract was prepared under sterile conditions and was added in 1, 2, and $3 \mathrm{~mL}$ to $100 \mathrm{~g}$ hamburger samples. A group of samples was prepared to be used as treatment sample, while a group was stored at $4^{\circ} \mathrm{C}$ and $-18^{\circ} \mathrm{C}$. The samples were kept in refrigerator for one and two weeks and they were frozen for one, two and three months and then subjected to microbial tests.

Results: Statistical evaluation of the first and second week samples indicated a significant growth decreased by all the 1, 2, and 3-mL extracts. In treatment of one, two and three-month samples, the growth of S. aureus was significantly decreased by the 2 and 3-mL extracts. The 1-mL extract was effective in decreasing the growth, and a significant difference was observed in treatments with 2 and 3-mL extracts. However, there was no significant difference between the two and three-month samples, though they were significantly different from the one-month samples. After evaluations, treatment with the 2-mL extract was found to be the best one.

Conclusions: Garlic aqueous extract has antibacterial properties against S. aureus present in hamburger. Moreover, garlic aqueous extract can be used not only as a flavor but also as a natural additive for hamburger. In addition, garlic has antibacterial properties against other Gram-positive and Gram-negative bacteria, which must be investigated in further studies.
\end{abstract}

Keywords: Antibacterial Effect; Garlic; Staphylococcus aureus; Hamburger

\section{Background}

Consumption of red meat and meat products has been dramatically increased all over the world. Among foods, hamburger is a very popular ready-to-eat and/or readyto-cook meal as it is delicious and enjoyable with an easy consumption method plus being prepared with or without added salt and seasonings $(1,2)$. A retail sale of fast food hamburgers has turned into a big business. Americans consume nearly five billion hamburgers each year, equal to 1.2 billion pounds of meat (3). Lipid oxidation and growth of microbes during the maintenance period are regarded as two important factors, affecting the quality of this food material, and are among the concerns of hamburger producers, since they may have negative effects on the odor and taste of hamburger, consequently decreasing the number of consumers $(1,4)$. Although application of antioxidants and antibacterials with chemical origins are useful for maintaining the quality, increased maintenance duration, prevention from lipid oxidation, and economic loss can have adverse effect on health of this product and by virtue of standards, using such materials in hamburger is prohibited.

One of the reasons for the consumers' high interest in hamburger rather than other meat products such as sausages is lack of chemical additives in hamburger, which increases the health level of this product. Pathogens related to food poisoning, which can be isolated from foods with animal origins such as meat and meat products (like hamburger), are specific types of bacteria called Salmonella serotypes, Staphylococcus aureus, Listeria monocytogenes and Escherichia coli $\mathrm{O} 157$ : $\mathrm{H} 7(1,2,5,6)$. They can be transferred to the water surface of carcasses when cattle is slaughtered (6). This highlights the necessity of studying the application of natural additives such as garlic. Garlic is a main component of hamburger which is used

Copyright (C) 2014,Ahvaz Jundishapur University of Medical Sciences; Published by Kowsar. This is an open-access article distributed under the terms of the Creative Commons Attribution-NonCommercial 4.0 International License (http://creativecommons.org/licenses/by-nc/4.0/) which permits copy and redistribute the material just in noncommercial usages, provided the original work is properly cited. 
to improve its odor and taste. Moreover, it has numerous medicinal usages and treatment properties, but rarely considered as a healthy food additive (7).

Garlic (Allium sativum L.) belongs to the Liliaceae family and falls within the group of onion, like mountain onion and shallot, and also has antibacterial activity against many common pathogenic bacteria $(8,9)$. Cavallito and Bailey (10) studied the chemical properties of garlic for the first time. They tried a host of methods for producing garlic extract and finally managed to produce the most important garlic compounds, called allicin, diallyl disulfide and alipin, which have less odor. They believed that extracted allicin, if used with ethyl alcohol solvent, would have more stability and antibacterial effects $(10,11)$. Among the organosulfur ingredients of garlic, S-allyl cysteine sulfoxide or alliin is the odorless compound. When garlic is cut, it is influenced by the alliinase enzyme, which is the cysteine sulfoxide lyase, and turns into allicin. All these substances are responsible for the strong smell of garlic and have antibacterial and antioxidant properties (12).

Allicin is the main biologically and biochemically active component of freshly crushed garlic which can easily be decomposed under the influence of heat and time into stable compounds. 2-propenesulfenic acid and tioacrolein are two important molecules derived from garlic, which in turn result in the formation of greater molecules including diallyl trisulfide and dithiin $(13,14)$. Generally, garlic is a potential antibiotic and shows an effective performance against the bacteria resistant to pharmaceutical antibiotics. In 1970's, Europeans tested the garlic extract on 10 species resistant to bacteria and yeasts and found it very resistant to Salmonella, S. aureus, Mycobacterium and Proteus species (15). In the present study, The antibacterial effects of garlic aqueous extract on 133 species of bacteria (both Gram-positive and Gram-negative) resistant to medicine, including S. epidermidis, S. aureus, Streptococcus pneumoniae, S. pyogenes, Haemophilus influenzae, S. typhi, Pseudomonas aeruginosa, E. coli, Shigella spp., Proteus spp. and 10 types of candida were studied. The minimum inhibition concentrations (MIC) or lowest densities of garlic aqueous extract that prevented the growth of microorganisms were determined in the present study (Table 1$)(16,17)$.

\section{Objectives}

This study aimed to investigate the antibacterial effects of garlic aqueous extract on $S$. aureus growth prevention in hamburger under the freezing condition, during one and two weeks as well as one, two, and three months.

\begin{tabular}{lc}
\hline Table 1. MIC Garlic Aqueous Extract $^{\mathrm{a}}$ & \\
\hline Type of Microorganism & MIC, $\mathbf{m g} / \mathbf{m L}$ \\
\hline Gram-positive bacteria & $15.6-48.3$ \\
Gram-Negative bacteria & $22.9-37.2$ \\
Molds and yeasts & $14.9-15.5$ \\
\hline
\end{tabular}

\footnotetext{
a Abbreviation: MIC, minimum inhibitory concentration.
}

\section{Materials and Methods}

\subsection{Preparing the Garlic Aqueous Extract}

Fresh garlic was purchased from a local market in Hamadan city, Iran, and 500 g of that was washed, peeled and washed again with sterile distilled water. Then, it was blended and crushed with $200 \mathrm{~mL}$ cool physiology serum $(0.9 \%)$ on top of chopped ice, next to fire flame to supply the sterilized condition. The obtained mixture was sterilized with an ordinary colander and then it was thinned with a flat, sterile $0.2-\mu$ syringe and stored at $-20^{\circ} \mathrm{C}(18,19)$.

\subsection{Hamburger Preparation}

Samples of hamburger were produced in accordance with the Institute of Standards and Industrial Research of Iran, Number 2304, under laboratory conditions. The raw materials were prepared from food stores and formulation of samples was performed under sterile conditions. The purchased grinded meat was blended on top of ice under sterile conditions with the colandered onion. Salt and common spicy foods along with flour in a specified ratio were blended with meat. Extracts of 1,2, and $3 \mathrm{~mL}$ were added to the samples. The prepared hamburgers were put into refrigerator in 100-g moulds and then the test for detection and counting $S$. aureus was performed with three repeats (20).

\subsection{Detection and Counting Staphylococcus au- reus}

During the detection stage, a suspension of the hamburger treatments was prepared and about 1-2 mL of the first dilution $\left(10^{-1}\right)$ was transferred to the test tube containing cooked meat culture medium with $10 \%$ additional salt ( $S$. aureus are halophilic bacteria). Afterwards, it was incubated at $37^{\circ} \mathrm{C}$ for 48 hours. A high percentage of salt contributed to the growth of $S$. aureus and if they were damaged during the process they could be repaired. Next, the incubated mixture was transferred to Baird-Parker Agar (BPA) where linear incubation was performed in a loop. S. aureus at incubation created black colonies with transparent areola after heating. To count S. aureus, after preparing the first dilution $\left(10^{-1}\right)$ and homogenizing $10 \mathrm{~g}$ of hamburger and $90 \mathrm{~mL}$ of sterile diluents (physiological serum), we tried to make further dilutions up to $10^{-8}$ to $10^{-10}$. The dilutions, cultured through surface method, were distinguished and the colonies containing S. aureus in $1 \mathrm{~g}$ of the sample were counted and evaluated $(12,21)$.

\subsection{Sensational Evaluation}

The formulated hamburgers were studied in laboratory by hedonic method with respect to color, appearance, odor, taste, crispiness, and structure. Sensational evaluation was performed by 15 panelists who studied 
all the mentioned factors in the indicator sample as well as in the samples with garlic aqueous extracts of 1, 2, 3 $\mathrm{mL}$, and finally categorized them as excellent, very good, good, acceptable and unacceptable levels. In this test, sample A was used as an indicator sample, while samples B, C and D contained 1, 2 and $3 \mathrm{~mL}$ garlic aqueous extracts, respectively. Then, the results were statistically studied based on complete random block plans $(22,23)$.

\subsection{Statistical Analysis}

Statistical evaluation was performed using SPSS software and the average treatments were compared using the Duncan's test.

\section{Results}

Results of studying the effects of garlic aqueous extract on growth of $S$. aureus in hamburger sample are presented in Tables 2 and 3 Figure 1 . The S. aureus count in the hamburger sample after the test and on zero days (immediately after adding garlic extract) was $2.6 \times$ $10^{6} \mathrm{CFU} / \mathrm{g}$. In the control group, $S$. aureus growth in the second week of the treatment significantly increased compared with the same group's value in the first week. Meanwhile, the 1, 2, and 3-mL treatments had no significant difference for the first week and two weeks, and all three concentrations of garlic liquid extract prevented the bacteria from growing and multiplying over time.

Growth of S. aureus in one and two-week samples indicated that all the extracts of 1,2 , and $3 \mathrm{~mL}$ significantly decreased the growth of $S$. aureus, with the effect of 3
$\mathrm{mL}$ extract being higher than the 1 and 2-mL extracts. However, considering a probable error of $5 \%$, there was no significant difference in effects of the extracts. The 2 and 3-mL extracts showed a significant difference when applied to the indicator sample, while application of the 1-mL extract did not. Statistical studying of the one, two and three-month samples indicated that 2 and 3-mL extracts with the probable error of $5 \%$ significantly decrease the $S$. aureus count, with no significant difference. The 1-mL extract was effective on decreasing the bacterial growth and showed a significant difference with the 2 and 3-mL extracts. There was no significant difference between the results from the two and threemonth samples and they were significantly different from the results of the one-month sample, so that less $S$. aureus growth was observed in the one-month sample. Statistical analysis in relation to the results obtained by panelist indicated that the $2-\mathrm{mL}$ garlic aqueous extract sample with the probable error of 5\% was more compatible than other samples, being significantly different. Therefore, hamburgers containing the 2 -mL garlic aqueous extract were regarded as the best treatments.

The storage methods comparison also revealed the fact that freezing is an excellent way to preserve meat products because meat has a flexible fiber structure which prevents from serious damages to tissues against freezing and reduces the growth of microorganisms. However, freezing does not completely remove the microorganisms and it can only reduce their process and functionality.

Table 2. Staphylococcus aureus in One and Two-Week Hamburger Samples a

\begin{tabular}{|c|c|c|c|c|c|}
\hline Treatments & Indicator Treatment & 1-mL Treatment & 2-mL Treatment & 3-mL Treatment & Standard \\
\hline Counted bacteria at $10^{-5}$, first week & $2 \pm 1 \mathrm{~b}, \mathrm{c}$ & $6.66 \pm 2.3^{c}$ & $0.00 \pm 0.00^{b}$ & $1 \pm 1.73^{b}$ & $10^{3}$ \\
\hline Counted bacteria at $10^{-5}$, second week & $14.33 \pm 13.05^{c}$ & $6.33 \pm 6.65^{b, c}$ & $0.66 \pm 1.15^{b}$ & $0.00 \pm 0.00^{b}$ & $10^{3}$ \\
\hline
\end{tabular}

Table 3. Staphylococcus aureus in One, Two, and Three-Month Hamburger Samples a

\begin{tabular}{|c|c|c|c|c|c|}
\hline Treatments & Indicator Treatment & 1-mL Treatment & 2-mL Treatment & 3-mL Treatment & Standard \\
\hline Counted bacteria at $10^{-3}$, first month & $1 \pm 1.73^{b}$ & $0.33 \pm 0.57^{b}$ & $1 \pm 1^{b}$ & $0.33 \pm 0.57^{b}$ & $10^{3}$ \\
\hline Counted bacteria at $10^{-3}$, 2nd month & $121.33 \pm 23.79^{C}$ & $95.67 \pm 9.71^{d}$ & $5.67 \pm 4.04^{b}$ & $4.33 \pm 1.52^{b}$ & $10^{3}$ \\
\hline Counted bacteria at $10^{-3}, 3 \mathrm{rd}$ month & $120.33 \pm 13.5^{C}$ & $111.67 \pm 11.59^{d}$ & $3 \pm 2.64^{b}$ & $2.67 \pm 1.52^{b}$ & $10^{3}$ \\
\hline
\end{tabular}

a Data are presented as mean \pm SD. The Number of Bacteria is indicated (CFU/g) in $1 \mathrm{~g}$ of Contaminated Food. To calculate the numbers they should be multiplied by $10^{4}$

b Sample A.

c Sample C.

d Sample B. 
Figure 1. Staphylococcus aureus in One and Two-Week, and One, Two, and Three-Month Hamburger Samples

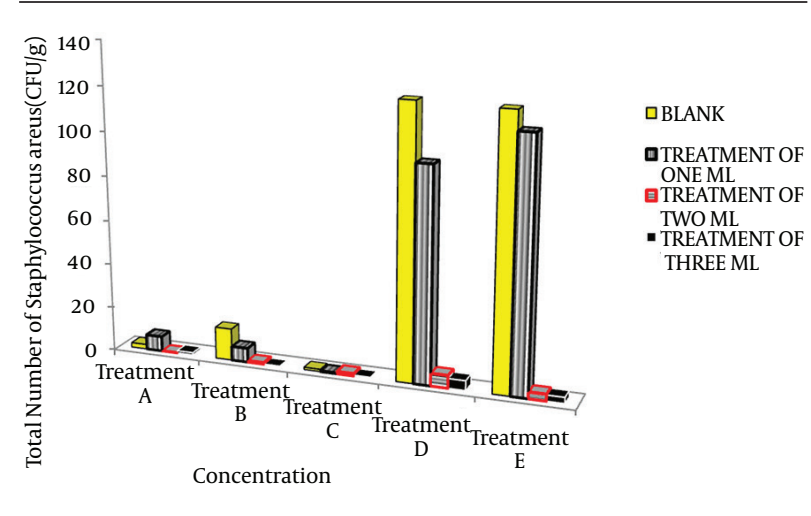

Treatment A, first week storage in refrigerator; treatment B, second week storage in refrigerator; treatment $\mathrm{C}$, first month storage in freezer; treatment $\mathrm{D}$, second month storage in freezer; treatment $\mathrm{E}$, third month storage in freezer.

\section{Discussion}

S. aureus is a Gram-positive, catalase-positive, aerobic and non-aerobic, halophilous, and immobile bacterium, capable of manitol fermentation. This bacterium has an irregular cluster shape and is a member of the Micrococaceae family and yeast under glucose aerobic conditions, and is killed at over $62^{\circ} \mathrm{C}$ (pasteurization temperature), with the ability to tolerate this temperature at least half an hour. Existence of golden S. aureus in food is regarded to as a potential danger which results in food poisons, due to existence of a nauseant polypeptide called enterotoxin $(21,24)$. Researches have indicated S. aureus as a very sensitive bacterium to aqueous and alcoholic extracts. Fujisawa et al. (14) reported chemical and biological stability of garlic aqueous and alcoholic extracts and their effects on both Gram-positive (S. aureus) and Gram-negative (E. coli) bacteria.

It was found that alcoholic garlic extract was much more stable and more effective than the aqueous extract. However, tests revealed that the antimicrobial activity of garlic is totally dependent on the allicin compound, which is three times more effective on Gram-positive bacteria than Gram-negative ones. Such results will be accounted for the membrane lipid content of these two bacteria because $E$. coli has a membrane lipid content 10 times higher than S. aureus, making allicin unable to reach the goal, as they are trapped in this lipid content. In previous surveys by Deresse (12) on the antibacterial effects of garlic extracts on preventing the growth of $S$. aureus in vitro, 30 different species of $S$. aureus were isolated and the Ethiopian garlic (A. sativum L.) aqueous extracts effects were studied on them.

It was indicated that MIC and garlic aqueous extract shall be more than $7.5 \mathrm{mg} / \mathrm{mL}$ to prevent bacterial growth. It also became clear that if we had autoclaved the garlic aqueous extract under the temperature of $121^{\circ} \mathrm{C}$ for
15 minutes, it would lose its efficiency on any strains of S. aureus and would not be effective anymore. Notably, antimicrobial properties of raw garlic under room temperature and garlic kept at $-10^{\circ} \mathrm{C}$ were similar and the fresh garlic had grater effects. Studying the antimicrobial properties of garlic indicated that garlic is full of anion compounds including nitrates, chlorides, sulfides and organosulphur compounds that can be easily resolved in water and are responsible for antibacterial properties (25). In addition, several studies on garlic have indicated that allicin in garlic is the most important substance that creates antibacterial properties and limits the speed of RNA synthesis; however, the preliminary role of allicin is trapping RNA. Lipid is a part of S. aureus membrane, which helps the easy penetration of allicin into the membrane and consequently influences the RNA(12).

The statistical evaluation of $S$. aureus showed that hamburger samples of the three extracts of 1,2 , and $3 \mathrm{~mL}$ of garlic extract had a significant effect in reducing the $S$. aureus growth in all these three treatments. The maximum effect was observed by the third extract concentration and the extracts with 1 and $2 \mathrm{~mL}$ concentrations were also effective in reducing the S. aureus growth. Furthermore, in the present study, it was indicated that 1,2, and 3-mL garlic aqueous extracts were effective on destruction of $S$. aureus in hamburger, as the principal goal of garlic aqueous extract was to destroy this bacteria and prevent from performance of the protein inducing RNA synthesis.

It can be concluded that garlic aqueous extract has antibacterial properties against $S$. aureus present in hamburger. Moreover, garlic aqueous extract can be used not only as a flavor but also as a natural additive for hamburger. Garlic also has antibacterial properties against other Gram-positive and Gram-negative bacteria, which should be investigated in further studies.

\section{References}

1. Lee JW, Park KS, Kim JG, Oh SH, Lee YS, Kim JH, et al. Combined effects of gamma irradiation and rosemary extract on the shelf-life of a ready-to-eat hamburger steak. Radiat Phys Chem. 2005;72(1):49-56.

2. Passos MHCR, Kuaye AY. Influence of the formulation, cooking time and final internal temperature of beef hamburgers on the destruction of Listeria monocytogenes. Food Control. 2002;13(1):33-40.

3. Prayson B, McMahon JT, Prayson RA. Fast food hamburgers: what are we really eating? Ann Diagn Pathol. 2008;12(6):406-9.

4. Dossantosfogaca F, Santana L. Tocopherol in the lipid stability of tilapia (Oreochromis niloticus) hamburgers. Food Chem. 2007;105(3):1214-8.

5. Shahraz F, Dadkhah H, Khaksar R, Mahmoudzadeh M, Hosseini $\mathrm{H}$, Kamran M, et al. Analysis of antibiotic resistance patterns and detection of mecA gene in Staphylococcus aureus isolated from packaged hamburger. Meat Sci. 2012;90(3):759-63.

6. Ou D, Mittal GS. Double-sided pan-frying of unfrozen/frozen hamburgers for microbial safety using modelling and simulation. Food Res Int. 2006;39(2):133-44.

7. Sallam KI, Ishioroshi M, Samejima K. Antioxidant and antimicrobial effects of garlic in chicken sausage. Lebenson Wiss Technol. 2004;37(8):849-55.

8. Kuda T, Iwai A, Yano T. Effect of red pepper Capsicum annuum var. conoides and garlic Allium sativum on plasma lipid levels 
and cecal microflora in mice fed beef tallow. Food Chem Toxicol. 2004;42(10):1695-700.

9. Ankri S, Mirelman D. Antimicrobial properties of allicin from garlic. Microbes Infect. 1999;1(2):125-9.

10. Cavallito CJ, Bailey JH. Allicin, the Antibacterial Principle of Allium sativum. I. Isolation, Physical Properties and Antibacterial Action. JAm Chem Soc. 1944;66(11):1950-1.

11. Harris JC, Cottrell SL, Plummer S, Lloyd D. Antimicrobial properties of Allium sativum (garlic). Appl Microbiol Biotechnol. 2001;57(3):282-6.

12. Deresse D. Antibacterial effect of garlic (Allium sativum) on Staphylococcu aureus: An in vitro study. Asian J Med Sci. 2010;2(2):62-5.

13. Guo JJ, Kuo CM, Chuang YC, Hong JW, Chou RL, Chen TI. The effects of garlic-supplemented diets on antibacterial activity against Streptococcus iniae and on growth in orange-spotted grouper, Epinephelus coioides. Aquaculture. 2012;33(38):364-5.

14. Fujisawa H, Suma K, Origuchi K, Kumagai H, Seki T, Ariga T. Biological and chemical stability of garlic-derived allicin. J Agric Food Chem. 2008;56(11):4229-35.

15. Bergner P, Rocklin CA. antibiotic and immune properties. Medic Herbalism.1995;1(1).

16. Yin MC, Chang HC, Tsao SM. Inhibitory effects of aqueous garlic extract, garlic oil and four diallyl sulphides against four enteric pathogens.J Food Drug Anal. 2002;10(2):120-6.

17. Iwalokun BA, Ogunledun A, Ogbolu DO, Bamiro SB, Jimi-Omojola J.
In vitro antimicrobial properties of aqueous garlic extract against multidrug-resistant bacteria and Candida species from Nigeria. $J$ Med Food. 2004;7(3):327-33.

18. Jafari H, Jahani Hashemi H, Abbasi E, Shahidi M. Effect of a queous Allium sativum L. extract on the rat and contraction of isolated atrial of mele rate after administration of adrenaline. Iran J Med Aromat Plnt. 2006;22:42-6.

19. Hajzadeh MR, Tavakol Afshari J, Ghorbani A, Shakeri MT. The effects of aqueous extract of garlic (Allium sativum L.) on laryngeal cancer cells (Hep-2) and L929 cells in vitro. J Med Plants. 2006;5(18):4148.

20. Anonymous . Frozen raw hamburger. Iran Stand Inst Ind Res. 2007.

21. Shabani S. Quality Control of Food Microbiology.South of Tehran Branch: Islamic Azad University Publications; 2008.

22. Didari Khamseh Motlagh M. Qualitative Assessment of Hamburger with 4 Different Formulations during Maintenance Period in Cold Warehouse. Inst Nutr Food Techn. 1992.

23. Vats BM. Methods of Sensational Evaluation of Foods.Tehran-Iran: Institute of Food Industry Research Publications; 1998.

24. Karim G. Microbiological Examination of Foods.Iran: Publications of University of Tehran; 2003.

25. Shobana S, Vidhya VG, Ramya M. Antibacterial activity of garlic varieties (ophioscordon and sativum) on enteric pathogens. Curr. Res. J. Biol. Sci. 2009;1(3):123-6. 